\title{
DESIGN AID FOR NUCLEAR FUEL AND COOLANT SYSTEM DURING LOCA
}

\author{
Anil Kumar Saxena \\ $\mathrm{PhD}$ in Chemical Engg. IIT MUMBAI \\ Ex. Research Reactor Services Division, BARC, Mumbai, 400085
}

\begin{abstract}
Design of nuclear fuel and coolant system for nuclear reactors has undisputable bearing on the aspects present during Loss of Coolant Accident (LOCA). In-depth knowledge of rewetting phenomenon and its successful application on LOCA in nuclear reactors is the need of the hour due to severity of the consequences which follow after LOCA. The paper highlights various aspects namely (1) Application of rewetting in innovative technology (2) Severe reactor accident management (3) Arresting nuclear waste discharge (4) Quality assurance checks on Emergency Core Cooling System (ECCS) and (5) Prevention of nuclear fuel clad softening.
\end{abstract}

Key Words: Guillotine Break, Rewetting, LOCA, Softening, ECCS

\section{INTRODUCTION}

Rewetting is explained as follows in a generalised manner: A particular material is considered initially wet. It is dried to attain some goal. It is further wetted to achieve different goal. The goal can be mitigation of consequences of LOCA in nuclear reactors, improvement in strength of materials, enhancing contact of liquid with a surface using rewetting/wetting agent. When the surface is wetted second time it is said to be rewetted. In general during rewetting the surface temperature lowers considerably. Rewetting of hot surface by coolant is of great importance for emergency cooling of nuclear fuel rods in nuclear reactors following a loss of coolant accident (LOCA). When the hot surface is at a temperature higher than the rewetting temperature the coolant does not wet the hot surface. Rewetting of the surface with the coolant occurs when the hot surface temperature falls below the rewetting temperature. In the process a wet front is formed, which moves along the length of the hot surface. When LOCA occurs the annulus around clad gets fully voided. Rewetting is a complex phenomenon. Devoting more space to explain rewetting will be out of scope of this paper. With this introductory remark explanation/discussion of different cases mentioned in abstract will form main body of paper.

\section{APPLICATION OF REWETTING IN INNOVATIVE TECHNOLOGY}

It is essential to understand the theoretical part of rewetting "Saxena et. al, (2015)" in view of applications of rewetting. A hot cylindrical claded nuclear fuel concentric to a tube with continuous heat generation in the fuel is considered. Water as coolant flows in the annulus. Let us assume a case when LOCA occurs. When water enters in annulus gradual cooling of clad occurs. When clad temperature reduces to rewetting temperature wet front is formed. Rewetting velocity is defined as rate of propagation of wet front. The clad is rewetted/cooled to the extent that its temperature lowers to a value where the surface has no chance of developing even a very fine size crack. The innovative technology related with rewetting is presented in Table 1.

\section{SEVERE REACTOR ACCIDENT MANAGEMENT}

Walker, SP et al, (2012) emphasized the urgency of reflooding of the core to quench overheating fuel following LOCA in Light Water Reactors (LWRs). Bottom flooding conditions in nuclear reactor with vertical fuel correspond to the state when coolant direction is from bottom to top during LOCA. Severe accident may follow under these conditions. A postulated initiating event (PIE) leading to double ended guillotine break in the pipes upstream to reactor core with vertical fuel channels is considered. Subsequent stages e.g. reduction of flow/pressure in the fuel channel and injection of flow from emergency core cooling system (ECCS) from location upstream to core are also taken into account. After introduction of ECCS coolant, gradually formed wet front remains on its way to the top of clad and rupture in clad is considered to take place. It is further assumed that the flow from ECCS could not be sufficient because the clad gets rupture at a location where the wet front could not reach. This may be noted that the rupture of 


\section{International Journal of Engineering Applied Sciences and Technology, 2020 \\ Vol. 4, Issue 12, ISSN No. 2455-2143, Pages 452-458 \\ Published Online April 2020 in IJEAST (http://www.ijeast.com)}

clad may occur in more than one channel also. This is a case of severe accident as it may result release of enormous amount of radiation and activity in environment and destruction to the nuclear plant. Accident management (AM) is defined as those actions that can be taken by the plant operating staff to prevent accidents or mitigate their consequences. Its objective is to further reduce the risk of plant damage and minimize radioactive release to the environment. Computer Code was developed to manage severe accidents following LOCA. A hot tube/rod concentrically located in another tube of same length was considered. Fig. 1 shows radial and axial grid and nodes used in fuel, gap and clad. $\mathrm{M}$ and $\mathrm{N}$ are total number of axial and radial nodes respectively.

\section{IIIa. Description of Model}

"Sahu S. K. et. al, (2009)" applied Heat Balance Integral Method (HBIM) for a comprehensive analysis of a three region model for conduction controlled rewetting of hot surfaces. Two region model will be considered in this paper. Fig. 1 shows axial and radial grids and nodes at intersection of grid lines. First column of axial nodes starts at distance of $\Delta R / 4$ from centre line of assembly. One column of single node is located at the centre of gap. Last column of axial node is located at a distance of $\Delta \mathrm{R}$ from outer surface of clad.

IIIb. Assumptions:

(i) Two regions exist on outer surface of clad: First, wetted region at upstream to rewetting front second, dry region at downstream to rewetting front.

(ii) A value of heat transfer coefficient (HTC) is considered in wetted region and HTC in dry region is zero.

(iii) No heat is transferred through ends of fuel, gap and clad and through outer surface of outer tube.

(iv) Thermal conductivity of fuel, gap and clad is a function of temperature.

(v) Initially gap is filled with Helium. Afterwards during LOCA gap is taken filled with mixture of Helium, Xenon and Krypton.

(vi) There is no angular variation of temperatures in fuel, gap and coolant at a given height from bottom of assembly.

IIIc. Numerical Solution and Results

Two dimensional heat conduction equation, Eq. (1) in cylindrical coordinates and in dimensionless form is given below: This equation is applicable for fuel, gap and clad of a nuclear reactor fuel assembly.

$$
\frac{\partial}{\partial R}\left[R \frac{\partial \theta}{\partial R}\right]+\frac{\partial}{\partial Z}\left[R \frac{\partial \theta}{\partial Z}\right]=-R P e\left[\frac{\partial \theta}{\partial Z}+S t\right]
$$

Total number of 29 locations of nodes with different boundary conditions are identified. Eq. (1) is integrated for each location and numerical equation is derived. Equations for other nodes were also derived using similar steps. Eq. (2) is obtained by equating the heat transferred from wetted region to coolant to the heat transferred from dry region of fuel, gap and clad to wetted region of the same.

Eq. (2) is solved with an initial value of HTC. Output temperatures are checked. An axial node on the outer surface of clad, namely $\mathrm{M}$ is identified as the last node in the rewetted nodes. Difference of LHS and RHS of Eq. (2) is computed for M. If the difference is more than a specified limit, Eq. (1) is again solved with higher HTC which is obtained by previous HTC multiplied by temperature at node $(\mathrm{M}+1)$. The process is repeated and is stopped when difference of LHS and RHS of Eq. (12) converges to specified value.

$$
\begin{aligned}
& R_{3} B i \int_{0}^{L_{w}} \theta_{R_{3}} d Z=P e_{f} \int_{0}^{R_{1}} R\left(\theta_{L}-\theta_{0}\right) d R+ \\
& P e_{g} \int_{R_{1}}^{R_{2}} R\left(\theta_{L}-\theta_{0}\right) d R+P e_{c} \int_{R_{2}}^{R_{3}} R\left(\theta_{L}-\theta_{0}\right) d R+ \\
& \frac{S t_{f} P e_{f} R_{1}^{2} L}{2}
\end{aligned}
$$

As the water is injected in the annulus from bottom, heat transfer from hot tube to water/steam is through following modes: (i) Single phase forced convection, (ii) Nucleate boiling, (iii) Transition boiling/Film boiling/Radiation and (iv) Precursory cooling. The rewetting process is split in two parts: Part I: When water is injected in annulus first refilling front is formed. From this time to the time when rewetting front is formed. Part II: After rewetting front is formed. Heat transfer conduction equation was solved by forward marching technique for fuel, gap and clad with appropriate initial and boundary conditions. Precursory cooling is effective on partial/full nodes which fall downstream to refilling front/rewetting front. Details of the code is outside the scope of this paper and are available in "Saxena, et. al. , (2008)"

The results obtained by execution of code for condition when fuel is with clad are given in Table- 
2. It is clear from Table 2 that minimum flow rate(s) required to prevent softening are acceptable as they are substantiated by the fact that the rewetting velocities between program and other researcher's work are reasonably close.

\section{ARRESTING NUCLEAR WASTE DISCHARGE}

This section emphasizes that rewetting process arrests the nuclear waste discharge which otherwise would have generated had the portion of clad is left unrewetted. A method is employed to arrest the temperature of vertical nuclear fuel-clad so as to keep clad fairly below its softening temperature. Objective is to control the generation of nuclear waste as a result of split or rupture in clad. A split or rupture occurring in nuclear fuel clad of operating nuclear reactors is source of solid, liquid and gaseous nuclear waste. The magnitude of this waste can be enormous and sometimes it may be difficult to handle this waste. The phenomenon of rewetting of hot surface by coolant is of great importance for emergency cooling of nuclear fuel rods in nuclear reactors following a loss of coolant accident (LOCA). This gives us a method to control occurrence of split or rupture in clad and thus to arrest the accidental discharge of nuclear wastes. One of the important applications of rewetting is to predict minimum flow rate required to introduce in annular channel following LOCA so as to keep clad fairly below the softening temperature. Two approaches: (i) Conduction controlled rewetting analysis and (ii) Analysis considering fluid thermal hydraulics in addition to tube wall axial conduction, have been used in general by investigators for the analysis of rewetting of hot surfaces. Most of the investigators have followed the approach of conduction controlled rewetting analysis. This is because the rewetting velocity does not differ much when thermal hydraulic aspects are also added explicitly in the conduction controlled analysis. Therefore, conduction controlled analysis has generally been used for the prediction of rewetting velocity.

\section{QUALITY ASSURANCE CHECKS ON}

\section{EMERGENCY CORE COOLING SYSTEM (ECCS)}

Flow rate required for ECCS should never be lower than a specific value. If it is lower than the specific value the temperature of clad will reach to softening temperature and clad integrity will be lost. Therefore quality assurance check on flow rate of ECCS is very important. It is essential to protect the staff of a nuclear reactor from all types of radiations. There can be many sources of radiation in nuclear reactor. This section is devoted on one source of radiation caused by loss of integrity of clad. The integrity of clad is lost when its temperature reaches to softening temperature during reactor operation and during accident conditions such as LOCA. Integrity of clad is lost during reactor operation due to the occurrence of split or rupture of the clad of a fuel rod. This split or rupture normally occurs when there is formation of void due to local boiling. This results in lowering of HTC causing rise in temperature of clad. Thus split or rupture of clad results. During LOCA the clad temperature may rise beyond rewetting temperature. When ECCS water enters into the annular passage between outer tube and inner tube (representing clad), in depth analysis is required on cooling of clad when the wet front is also formed. Bubble formations in the annular gap are inevitable.

To summarise, following checks are required:

(1) On coolant flow rate and coolant temperature particularly at exit of fuel rod coolant passage.

(2) However when LOCA occurs the scenario is much different. The annulus in a rod gets fully voided. The flow of ECCS cooling water should be such magnitude that the wet front should reach at the top of clad before top clad temperature reaches to a temperature below the softening temperature with reasonable margin. Therefore ECCS cooling water flow should be checked.

\section{PREVENTION OF NUCLEAR FUEL CLAD SOFTENING}

Specified Emergency Core Cooling System (ECCS) flow rate is testimony of clad reaching to temperature lower than its softening temperature during loss of coolant accident (LOCA) in nuclear reactors. Coolant channel(s) of nuclear reactors with vertical fuelassemblies e. g. LWRs gets voided in a short time as a result of double ended rupture in coolant pipeline. There is rapid and almost steep rise in Clad temperature due to stored energy and decay heat if ECCS flow rate is less than a specified value. This section will bring out the fact that if coolant flow is less than a specified value the wet front will not reach the top of the clad. This will result some unrewetted clad portion. As the heating of this unrewetted clad is continued it may result softening of clad. If it happens in many channels the integrity of clad as a whole will be lost. There will be high probability that severe accident will take place. Literature survey reveals 


\section{International Journal of Engineering Applied Sciences and Technology, 2020 \\ Vol. 4, Issue 12, ISSN No. 2455-2143, Pages 452-458 \\ Published Online April 2020 in IJEAST (http://www.ijeast.com)}

terms like thermal softening, flow softening, strain softening etc. The softening appearing in the paper is the one which is related with creep phenomenon. Material properties, for example creep are temperature dependent: at lower temperature the material is harder whereas at higher temperature it is softer. During reactor operation the Zircaloy-2 undergoes softening at temperatures around $973 \mathrm{~K}$ or above and melts at 2106 $\mathrm{K}$. A need is felt to study rewetting and softening on the same platform. This gives new dimension to the study on rewetting/softening.

\section{CONCLUSIONS}

(1) Flow of coolant from ECCS should always be greater than a specified value.

(2) The wet front should reach the top of clad in specified duration.

(3) Acceptable rate of rise of fuel temperature subsequent to LOCA will be different for different reactors.

\section{REFERENCES}

(1) Saxena A. K. et. al, (2015). Management of NPP Severe Accident by Prevention of Clad Softening, International Workshops on NPPs-Safety \& Sustainability , CANSAS \& IW - NRTHS.

(2) Ghosh A. K., Fundamentals of Paper Drying Theory and Application from - InTech cdn.intechweb.org/pdfs/19429.pdf.

(3) Saxena A. K. et. al. , (2008) Code RAMM for Rewetting on Vertical Nuclear Fuel clad, Indian Chemical Engineer, Vol. 50, No. 3.

(4) Carbajo Juan J. (1986) Parametric study on rewetting velocities obtained with a twodimensional heat conduction code' Nuclear Engg. and Design 92,69-87.

(5) Saxena A. K. et. al, (2013) Identification of Quench Region Heat Transfer Coefficient(s)' Proceedings of 22ISHMT-11ASME Conference held during Dec. 28-31 in IIT Kharagpur.
(6) Sahu S. K. et. al, (2009) A three-region conduction-controlled rewetting analysis by the Heat Balance Integral Method", International Journal of Thermal Sciences, 48, 2100-2107.

(7) Walker, SP et al, (2012) The rewetting of PWR fuel cladding during post-LOCA reflood: a proposed physical explaination for the micro-scale high-frequency sputtering observed, Proceedings of the institution of mechanical engineers Part AJournal of Power and Energy, Volume 226, IssueA3,384-397.

\section{NOMENCLATURES}

$\dot{\mathrm{Q}}$ Volumetric heat generation rate in the fuel $\left(\mathrm{kW} / \mathrm{m}^{3}\right)$

Bi Biot number $=\mathrm{HTC} \varepsilon / \mathrm{k}_{\mathrm{c}}$

Pe Peclet No $P e=\frac{\rho \varepsilon C u}{k}$

L Dimensionless height of fuel assembly $=1 / \varepsilon$

$\mathrm{R}$ Dimensionless radial distance $=\mathrm{r} / \varepsilon$

$\Delta \mathrm{R}$ Radial mesh size

St. Stanton No. for fuel

$\mathrm{Z}$ Dimensioless distance $=\mathrm{z} / \varepsilon$

$\Delta \mathrm{Z}$ Axial mesh size.

$\mathrm{T}$ Temperature

Greek Symbol

$\theta$ Dimensioless temperature $=\left(\mathrm{T}-\mathrm{T}_{\mathrm{i}}\right) /\left(\mathrm{T}_{\mathrm{o}}-\mathrm{T}_{\mathrm{i}}\right)$

$\varepsilon \quad$ Thickness of clad

Subscripts

1 Surface of fuel

2 Inner surface of clad

3 Outer surface of clad

c Clad

f Fuel

w Location of rewetting

s Saturation

o indicates rewetting temperature

i indicates inlet temperature

Table 1: Comparative information on different types of rewetting applications

\begin{tabular}{ccccc}
\hline S. No. & $\begin{array}{c}\text { Parameters/Field of } \\
\text { utility/Sub-headings } \\
\text { required during } \\
\text { modeling }\end{array}$ & $\begin{array}{c}\text { Application (1) at } \\
\text { high temperature, }\end{array}$ & $\begin{array}{c}\text { Application (2) } \\
\text { for studying } \\
\text { properties of } \\
\text { materials }\end{array}$ & $\begin{array}{c}\text { Application (3) } \\
\text { based on } \\
\text { Rewetting/Wetting Agent }\end{array}$ \\
\hline 1 & $\begin{array}{c}\text { Nuclear/Non nuclear } \\
\text { Applications }\end{array}$ & Nuclear & Non nuclear & Non nuclear \\
\hline
\end{tabular}


International Journal of Engineering Applied Sciences and Technology, 2020

Vol. 4, Issue 12, ISSN No. 2455-2143, Pages 452-458

Published Online April 2020 in IJEAST (http://www.ijeast.com)

\begin{tabular}{|c|c|c|c|c|}
\hline 2 & Starting Equation & $\begin{array}{l}\text { Applicable as it is } \\
\text { given in Eq. (1) in } \\
\text { II }\end{array}$ & $\begin{array}{c}\text { Theoretical work is } \\
\text { available "Ghosh A } \\
\text { K" }\end{array}$ & \\
\hline & & $\begin{array}{l}\bullet \text { will be } \\
\text { significant. }\end{array}$ & $\dot{Q}$ will be zero. & $\begin{array}{l}\text { *Modified Eq. (1) may be } \\
\text { tried since coating of } \\
\text { rewetting agents is used to } \\
\text { change the surface }\end{array}$ \\
\hline 3 & $\begin{array}{l}\text { Boundary } \\
\text { Conditions }\end{array}$ & $\begin{array}{l}\text { Will remain same as } \\
\text { existing }\end{array}$ & $\begin{array}{l}\text { Will change as per } \\
\text { surroundings }\end{array}$ & properties. $Q$ will be zero. \\
\hline 4 & $\begin{array}{c}\text { Conductive and } \\
\text { Convective Heat } \\
\text { transfer }\end{array}$ & $\begin{array}{l}\text { Boiling regime } \\
\text { considerations }\end{array}$ & Will be applicable & \\
\hline 5 & Phase Change & Will take place & $\begin{array}{l}\text { May or may not } \\
\text { take place }\end{array}$ & \\
\hline 6 & $\begin{array}{c}\text { Derivation of } \\
\text { Numerical Equations }\end{array}$ & $\begin{array}{l}\text { Will remain same as } \\
\text { existing }\end{array}$ & $\begin{array}{c}\text { Numerical } \\
\text { equations will be } \\
\text { derived after } \\
\text { considering control } \\
\text { volume of different } \\
\text { lengths. }\end{array}$ & \\
\hline 7 & $\begin{array}{l}\text { Gauss Seidel } \\
\text { Elimination } \\
\text { Technique }\end{array}$ & Applicable & $\begin{array}{l}\text { May also be } \\
\text { applicable }\end{array}$ & \\
\hline
\end{tabular}

* Common entry for all S. Nos. 2 to 7 
International Journal of Engineering Applied Sciences and Technology, 2020

Vol. 4, Issue 12, ISSN No. 2455-2143, Pages 452-458

Published Online April 2020 in IJEAST (http://www.ijeast.com)

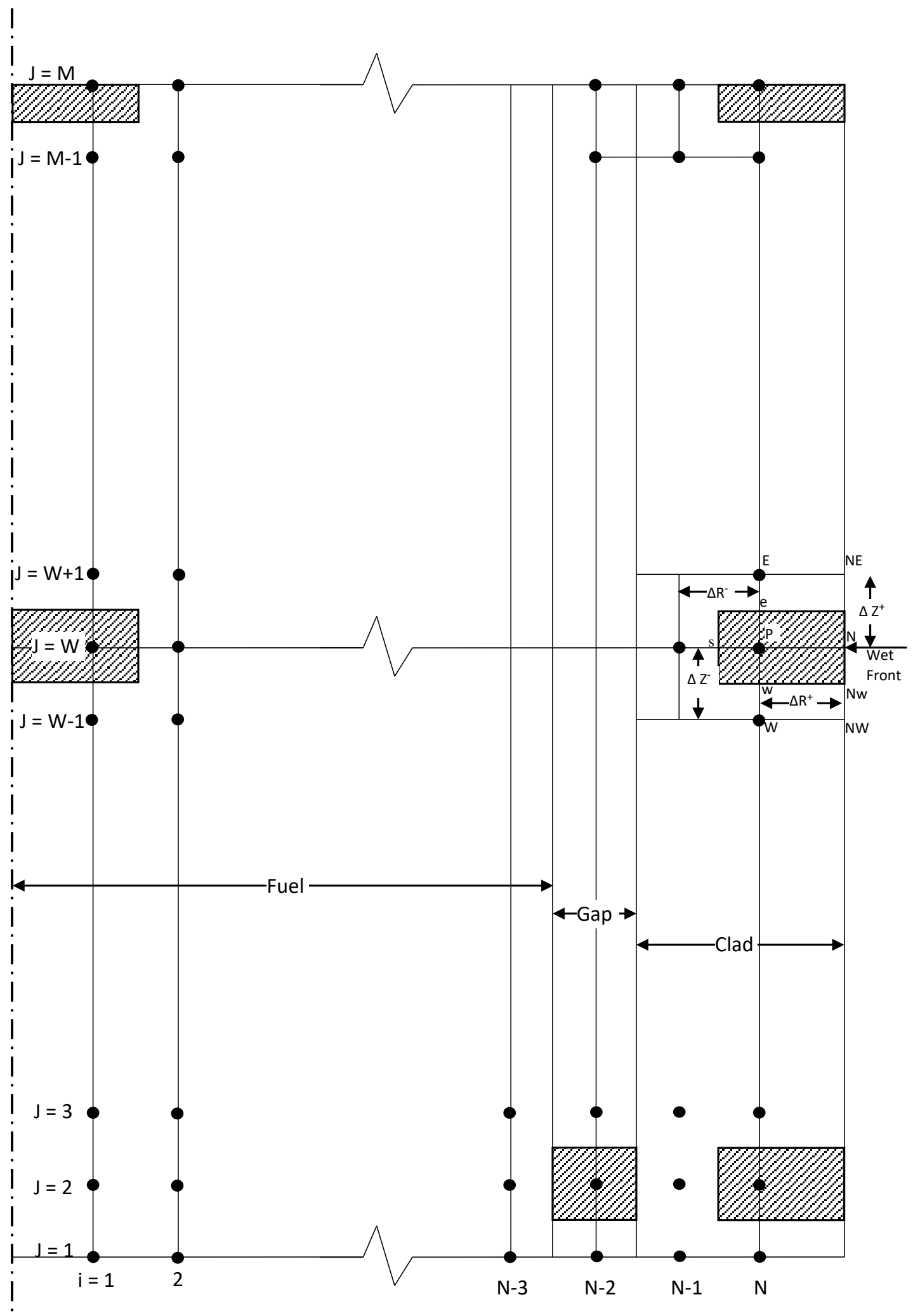


Fig. 1. Radial and axial grid and nodes used in fuel, gap and clad. $\mathrm{M}$ and $\mathrm{N}$ are total number of axial and radial nodes respectively. $\mathrm{W}$ is node at wet front.

Table 2: Comparison of Rewetting Velocities

Using Program and Other Researcher's Work

\begin{tabular}{|c|c|c|c|c|}
\hline S. No. & $\begin{array}{c}\text { Length of fuel pin, } \\
\text { mm/Material of } \\
\text { fuel/Clad }\end{array}$ & $\begin{array}{c}\text { Initial } \\
\text { Temperature } \\
\text { fuel/Clad } \\
{ }^{\circ} \mathrm{C}\end{array}$ & $\begin{array}{c}\text { Minimum } \\
\text { Flow Rate to prevent clad } \\
\text { softening } \\
\mathrm{m}^{3} / \mathrm{hr}\end{array}$ & $\begin{array}{c}\text { Rewetting Velocity } \\
\text { by present work/other researcher's } \\
\text { work } \\
\mathrm{mm} / \mathrm{s}\end{array}$ \\
\hline 1 & $\begin{array}{c}3030 / \mathrm{Natural} \\
\text { Uranium/ } \\
\text { Aluminium }\end{array}$ & $350 / 200$ & 0.0675 & $114.92 / 111.1$ \\
\hline 2 & $\begin{array}{c}500 / \mathrm{UO}_{2} / \\
\text { Zircaloy }\end{array}$ & $538 / 260$ & 0.21 & 127.89 \\
\hline 3 & $\begin{array}{c}500 / \mathrm{UO}_{2} / \\
\text { Zircaloy }\end{array}$ & $850 / 204$ & 0.21 & 13.65 to 17.46/12 “Carbajo Juan J., \\
$(1986)$ ”
\end{tabular}

